\title{
The effects of ozone on bacterial growth and thiol-disulphide homeostasis in vascular graft infection caused by MRSA in rats ${ }^{1}$
}

\author{
Barcin Ozturk', Tunay Kurtoglu", Selim Durmaz"I', Leyla Didem Kozacilv, Filiz Abacigilv, Bulent \\ Ertugrul ${ }^{\mathrm{V}}$, Ozcan Erel ${ }^{\mathrm{VII}}$
}

'Assistant Professor, Department of Infectious Diseases and Clinical Microbiology, University of Adnan Menderes, School of Medicine, Aydin, Turkey. Conception and design of the study, acquisition of data, technical procedures, manuscript preparation and writing.

"Associate Professor, Department of Cardiovascular Surgery, University of Adnan Menderes, School of Medicine, Aydin, Turkey. Conception and design of the study, acquisition of data, technical procedures, manuscript preparation and writing. "'Assistant Professor, Department of Cardiovascular Surgery, University of Adnan Menderes, School of Medicine, Aydin, Turkey. Design of the study, acquisition of data, technical procedures.

"VhD, Professor, Department of Medical Biochemistry, University of Yildirim Beyazit, School of Medicine, Ankara, Turkey. Biochemical assays, interpretation of data, manuscript writing.

${ }^{\vee}$ Associate Professor, Department of Public Health, University of Adnan Menderes, School of Medicine, Aydin, Turkey. Statistical analysis, interpretation of data.

${ }^{V 1}$ Associate Professor, Department of Infectious Diseases and Clinical Microbiology, University of Adnan Menderes, School of Medicine, Aydin, Turkey. Manuscript writing.

VIIProfessor, Department of Medical Biochemistry, University of Yildirim Beyazit, School of Medicine, Ankara, Turkey. Biochemical assays, interpretation of data, manuscript writing.

\begin{abstract}
Purpose: To investigate the microbiological, inflammatory and oxidant effects of adjuvant ozone administration in experimental rat vascular graft infection model which has not been previously investigated.

Methods: Forty adult Wistar rats were divided into Sham, Control, Vancomycin, Ozone, Vancomycin+Ozone groups. Grafts were inoculated with Methicillin-resistant Staphylococcus aureus (MRSA) strain and implanted subcutaneously. Rats were treated intraperitoneally with ozone and /or intramuscularly with vancomycin for 10 days. Grafts were evaluated by quantitative bacterial cultures. Blood samples were harvested for determination of thioldisulphide and cytokine profiles.

Results: There was no significant difference in bacterial counts between Control and Ozone Groups. In the Ozone Group median colony count was significantly higher than the Vancomycin and Vancomycin+Ozone Groups. Total thiol and disulphide levels increased and disulphide/ native thiol and disulphide/total thiol ratios decreased in Ozone Group significantly. Albumin levels decreased significantly in Vancomycin and Vancomycin+Ozone Groups compared to the Sham Group. IL-1 and TNF-alpha levels significantly increased in infected rats. Decreased levels of VEGF due to infection reversed by ozone therapy in control and vancomycin groups. Conclusion: We didn't observe any benefit of the agent on MRSA elimination in our model. Likewise, effects of ozone on thiol-disulphide homeostasis and inflammatory cytokines were contradictory.
\end{abstract}

Key words: Ozone. Staphylococcus aureus. Sulfhydryl Compounds. Vancomycin. Rats. 


\section{- Introduction}

Vascular graft infections are among the most important complications in vascular surgery with an estimated incidence of 1-6\%. Despite the significant improvement in the treatment and prevention of these infections, the mortality risk is still high reaching up to $70 \%$ in limb graft infections and to $75 \%$ in intraabdominal graft infections ${ }^{1}$.

Contamination of the vascular graft material generally occurs during the operative period or in the immediate postoperative period. Staphylococcus aureus (S. aureus) and Staphylococcus epidermidis (S. epidermidis) which are the most predominant microorganisms found in skin may easily contaminate the vascular grafts ${ }^{1}$. S. aureus and coagulase-negative staphylococci are the causative microorganisms in $70-90 \%$ of the postoperative cardiac, thoracic and vascular infections ${ }^{2}$.

Ozone $\left(\mathrm{O}_{3}\right)$, a useful disinfectant, is a naturally formed compound consisting of three oxygen atoms. The agent can potently inactivate bacteria, spores, and viruses within a few minutes ${ }^{3}$. Ozone is clinically effective in the treatment of infected wounds ${ }^{4}$. In several experimental infectious models, ozone therapy has been shown to have beneficial effects when applied as an adjunct to standard antibiotic treatment ${ }^{5}$.

Thiols are organic sulphur derivatives that contain sulfhydryl residues (-SH) at their active site. Thiols react easily with oxygencontaining free radicals to form disulphides. Once formed, the disulphide bonds can be reduced to thiol groups again, maintaining the thiol- disulphide balance. In infectious diseases, various inflammatory cells are activated and reactive oxygen species are produced as result of the struggle with microorganisms. Thiol-disulphide homeostasis and cytokine levels are also affected in this fight. There are very few studies investigating thiol-disulphide balance in infections ${ }^{6,7}$. Contrary to cytokine levels, the effect of ozone on the thiol-disulphide balance has not yet been well-studied in infection models.

In this experimental study we investigated the microbiological, inflammatory and oxidant effects of adjuvant ozone administration in $S$. aureus induced vascular graft infection. This is the first study to investigate the effect of ozone to thioldisulphide homeostasis in experimental model of infection.

\section{Methods}

The experimental design and protocol were approved by the Animal Care Committee of Adnan Menderes University (2012/092). The animal care was conducted in accordance with the National Institute of Health's Guide for Care and Use of Laboratory animals.

Adult male Wistar rats were (250-300g body weight) used in the study. The animals were housed at controlled room temperature $\left(24 \pm 2^{\circ} \mathrm{C}\right)$ with a 12 -h dark-light cycle and had free access to standard rat chow and tap water.

\section{Vascular graft infection model}

Under sterile conditions a gelatinesealed Dacron graft (Gelseal; SuzerVascutek Ltd, UK) was tailored to form $1 \mathrm{~cm}^{2}$ sized graft pieces. The rats were anesthetized with an intraperitoneal injection of ketamine hydrochloride $(90 \mathrm{mg} / \mathrm{kg}$, Ketalar, Pfizer, Turkey) and xylazine (3 $\mathrm{mg} / \mathrm{kg}$, Rompun, Bayer,Turkey). After shaving the hair on back of the animals the skin was cleaned with $10 \%$ povidone iodine solution and covered with sterile dressing. Through $1.5 \mathrm{~cm}$ long right paramedian incisions subcutaneous pockets were prepared according to previous reports ${ }^{8}$. Methicillin resistant S. aureus ATCC 43300 (MRSA) strain was used as the infecting 
organism. In our preliminary experiments, grafts implanted into subcutaneous pockets were inoculated with $1 \mathrm{ml}$ saline solution containing MRSA strain at a concentration of $2 \times 10^{7} \mathrm{CFU} / \mathrm{ml}$ using a sterile tuberculin syringe. On the 7th day, grafts were explanted then evaluated by quantitative cultures based on previous studies ${ }^{8}$. Our microbiologic evaluation of the preliminary work revealed that $2 \times 10^{7}$ $\mathrm{CFU} / \mathrm{ml}$ MRSA used in previous reports was not sufficient to ensure experimental graft infection since some of the examined grafts were not infected at all. Therefore, in our study protocol we inoculated the pre-implanted subcutaneous pocket grafts with $1 \mathrm{ml}$ saline solution containing MRSA strain at a concentration of $0.9 \times 10^{9} \mathrm{CFU} /$ $\mathrm{ml}$ (3xMcFarland) using a sterile tuberculin syringe ${ }^{9}$. The pockets were then closed by $5 / 0$ polypropylene sutures (Dogsan Ltd, Turkey). The animals were then returned to individual cages and examined daily for presence of local signs of perigreft inflammation.

\section{Study groups and protocol}

Animals were randomly assigned into five study groups each consisting of eight animals: Sham (S) group, Control (C) group, Vancomycin (V) group, Ozone $\left(\mathrm{O}_{3}\right)$ group and Vancomycin + ozone $\left(\mathrm{V}+\mathrm{O}_{3}\right)$ group.

- Sham Group: Grafts were not contaminated and no treatment was given.

- Control Group: Grafts were contaminated and no treatment was given.

- Vancomycin Group: Graftswere contaminated. Three days after the implantation vancomycin (Vancomycin hydrochloride; Hospira, UK) at a dose of $40 \mathrm{mg} / \mathrm{kg} / \mathrm{d}$ was administered through intramuscular (IM) route for seven days.

- Ozone Group: Grafts were contaminated. Ozonized oxygen was produced from medical oxygen by using an ozone gas processor (OZONOSAN Photonik 1014; Hansler GmbH, Iffezheim, Germany). Ozone concentrations were monitored in real time by a built
in-UV spectrometer. Three days after the contamination ozone/oxygen gas mixture (\%97 $\mathrm{O}_{2}+\% 3 \mathrm{O}_{3}$ ) was delivered via intraperitoneal (IP) route at a dose of $0.7 \mathrm{mg} / \mathrm{kg} / \mathrm{d}(70 \mu \mathrm{g} / \mathrm{ml})$ for seven days.

- Vancomycin + Ozone Group: Grafts were contaminated. Combinations of vancomycin and ozone therapies were applied for seven days.

In all groups grafts were explanted on the $10^{\text {th }}$ day after the implantation and animals were sacrificed via exsanguination.

\section{Assessment of infection}

VThe explanted grafts were placed in sterile tubes, washed in sterile saline solution, placed in tubes containing $10 \mathrm{ml}$ phosphate-buffered saline (PBS) solution and sonicated for $2 \mathrm{~min}$ to remove the adherent bacteria from the grafts. Quantification of viable bacteria was performed by serial 10 -fold dilutions $(0.1 \mathrm{ml})$ of the bacterial suspension on blood agar plates. All plates were incubated at $37^{\circ} \mathrm{C}$ for $48 \mathrm{~h}$ and evaluated for the presence of staphylococcal strain. The organisms were quantified by counting the number of colony forming units per plate $e^{8,10}$. The quantity of bacterial growth for each animal was assessed in terms of $\mathrm{CFU} / \mathrm{ml}$ and converted to $\log 10$ for statistical analysis.

\section{Biochemical analyses}

Blood samples centrifuged in the cold at $2300 x g$ for $10 \mathrm{~min}$. Serum samples were separated and stored at $-80 \mathrm{oC}$. Serum thioldisulphide profile tests were performed using a recently developed novel and automatic measurement method by using an automated clinical chemistry analyser (Roche, cobas 501, Mannheim, Germany). Serum native (-SH) and total thiol (-SH + $-\mathrm{S}-\mathrm{S}-)$ amounts were measured as a paired test. The subtraction of native from total thiol concentrations gave the 
disulphide (-S-S-) amounts. The disulphide/ native thiol, disulphide/total thiol and native thiol/total thiol ratios were also calculated ${ }^{11}$.

\section{Cytokines detections}

Serum IL-1, IL-4, IL-10, TNF- $\alpha$ were measured by enzyme-linked immunosorbent assay (ELISA) using eBioscience kits. VEGF levels were measured using Bioassay Technology Laboratory ELISA kit (Cat No: E0940Ra) according to the manufacturer's instructions.

\section{Statistical analysis}

Data were statistically analyzed using the SPSS 17.0 statistical program (SPSS Inc., Chicago, IL). Kolmogorov-Smirnov Test was used for examining the normality of distributions of the data. For data that were not normally distributed such as colony numbers for each group, the median and range values were indicated. Mann-Whitney $U$ and Kruskal Wallis tests were used to compare non-parametric continuous variables in independent groups. ANOVA test was used to compare the means of thiol, disulphide and Mann-Whitney $U$ test was used to statistically analyse interleukin levels in sera. A 0.05 type 1 error level was used to infer statistical significance.

\section{- Results}

There was no mortality in any of the study groups. No bacterial growth was observed in rats in the sham group (Data not shown). The quantities of bacterial growth for each animal are presented in Table 1 and the median colony counts for each group except the sham group are shown in Figure 1. The bacterial count in the Group C was significantly higher when compared to Groups $\mathrm{V}$ and $\mathrm{V}+\mathrm{O}_{3}$ $(p=0.001)$. There was no statistically significant difference in terms of median colony counts between the Groups V and $V+O_{3}(p=0.165)$. It was observed that although statistically nonsignificant, there were more colonies in the Group $\mathrm{V}+\mathrm{O}_{3}$ as compared to Group V (Table $1)$. Median colony count was significantly higher in the $\mathrm{O}_{3}$ Group than the $\mathrm{V}$ and $\mathrm{V}+\mathrm{O}_{3}$ Groups $(p=0.001)$. In the $\mathrm{O}_{3}$ Group median colony count was also higher compared to the C Group, however this difference was not statistically significant (Figure 1).

Table 1 - Quantitative bacterial culture results.

\begin{tabular}{lcccc} 
Animals & $\mathrm{C}$ & $\mathrm{V}$ & $\mathrm{O}_{3}$ & $\mathrm{~V}+\mathrm{O}_{3}$ \\
\hline R1 & 5.2201 & 0 & 5.1760 & 2.7923 \\
R2 & 4.2648 & 0 & 5.7323 & 3.7781 \\
R3 & 5.0413 & 3.3181 & 5.4149 & 0 \\
R4 & 5.1335 & 0 & 5.2552 & 4.4771 \\
R5 & 5.4048 & 3.8920 & 5.6020 & 3.4771 \\
R6 & 5.1702 & 3.1522 & 4.5390 & 2.1335 \\
R7 & 4.7481 & 0 & 5.5078 & 3.3096 \\
R8 & 6.1139 & 3.1522 & 5.1986 & 3.3263 \\
\hline
\end{tabular}

The quantity of bacterial growth for each animal was assessed in terms of CFU/ml and converted to log10. (C) Control group, (V) Vancomycin group, $\left(\mathbf{O}_{3}\right)$ Ozone group, $(\mathbf{V}+\mathbf{O})$ Vancomycin + ozone group. 


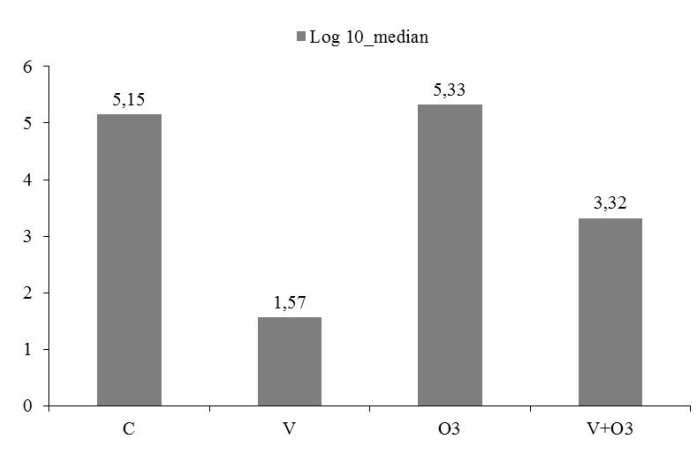

Figure 1 - Median colony counts for each group except the Sham (S) Group.

Total thiol levels were higher in Group O3 compared to the Groups C $(p=0.003)$, $\mathrm{V}(\mathrm{p}=0.001)$ and $\mathrm{V}+\mathrm{O}_{3}(\mathrm{p}=0.002)$ (Figure 2). Compared to the Group $S$ total thiol levels were higher in Ozone Group $\mathrm{O}_{3}$ and lower in $\mathrm{C}, \mathrm{V}$ and $\mathrm{V}+\mathrm{O}_{3}$ Groups. However, these findings were not statistically significant. Native thiol $(-\mathrm{SH})$ levels increased significantly only in Group $\mathrm{V}+\mathrm{O}_{3}(\mathrm{p}=0.037)$ compared to controls. In Group $\mathrm{O}_{3}$, disulphide (-S-S) levels measured higher compared to the Control ( $C ; p=0.008)$, Vancomycin ( $V ; p=0.000)$ and Vancomycin + Ozone $\left(\mathrm{V}+\mathrm{O}_{3} ; \mathrm{p}=0.001\right)$ Groups. Disulphide (-SS) levels were higher in $\mathrm{O}_{3}$ but lower in Groups $\mathrm{C}, \mathrm{V}$ and $\mathrm{V}+\mathrm{O}_{3}$ compared to Group S. These differences were not statistically significant. In $\mathrm{V}$ and $\mathrm{V}+\mathrm{O}_{3}$ Groups compared to the $\mathrm{O}_{3}$ Group, disulphide/native thiol (-S-S/-SH) ratios were lower ( $p=0.002, p=0.003$, respectively). Disulphide/total thiol (-S-S/(-S-S+-SH)) ratios in Groups $\mathrm{V}$ and $\mathrm{V}+\mathrm{O} 3$ were also lower compared to the $\mathrm{O}_{3}$ Group $(p=0.001$ and $p=0.002$, respectively). Native thiol/total thiol $(-\mathrm{SH} /(-\mathrm{S}-\mathrm{S}+-\mathrm{SH}))$ ratios were higher in Groups $V(p=0.001)$ and $V+O_{3} \quad(p=0.002)$, compared to the Group $\mathrm{O}_{3}$. Albumin levels were lower in Groups V $(p=0.000)$ and $V+O_{3}(p=0.001)$ compared to Group S (Figure 3). In Group V albumin levels were lower compared to the Controls $(p=0.000)$.

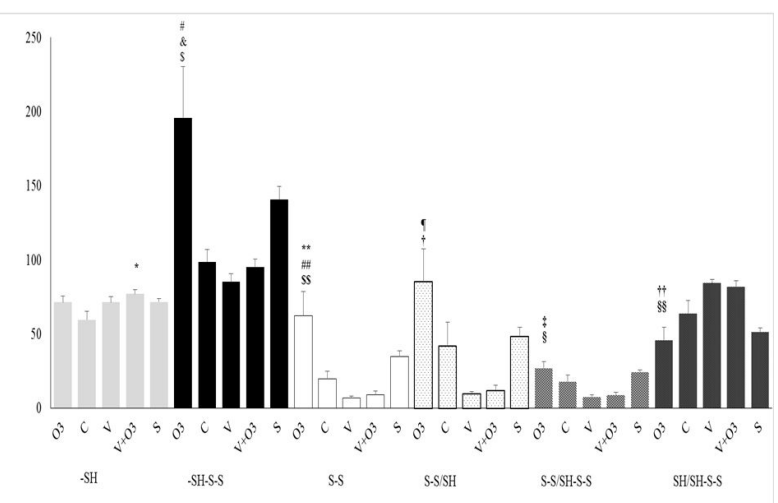

Figure 2 - Serum thiol-disulphide profile. Native thiol (-SH), Total thiol (-SH $+-\mathrm{S}-\mathrm{S})$, Disulphide $(-S-S)$, Native thiol/total thiol ratios $(-\mathrm{SH} /(-\mathrm{S}-\mathrm{S}+-$ $\mathrm{SH})$, Disulphide/native thiol ratios (-S-S/-SH) and Disulphide/total thiol ratios (-S-S/(-S-S+-SH) were shown in the study groups. Statistical significance between the groups is shown by symbols: ${ }^{*} \mathrm{C} v s \mathrm{~V}=\mathrm{O}_{3}$ $(p=0.037), \# O_{3}$ vs $C(p=0.003), \& O_{3}$ vs $V(p=0.001)$, $\$ \mathrm{O}_{3} \mathrm{~V}+\mathrm{O}_{3} \quad(p=0.002),{ }^{* *} \mathrm{C}$ vs $\mathrm{O}_{3} \quad(p=0.008), \# \#$ $\mathrm{O}_{3}$ vs $\mathrm{V}(\mathrm{p}=0.000), \$ \$ \mathrm{O}_{3}$ vs $\mathrm{V}+\mathrm{O}_{3} \quad(p=0.001), \mathrm{O}_{3}$ vs $V(p=0.002), \uparrow O_{3}$ vs $V+O_{3} \quad(p=0.003)$, †† $O_{3}$ vs $V(p=0.001), \S O_{3}$ vs $V+O_{3}(p=0.002)$, †† $O_{3}$ vs $V$ $(p=0.000), \S \S O_{3} v s V+O_{3}(p=0.002)$.

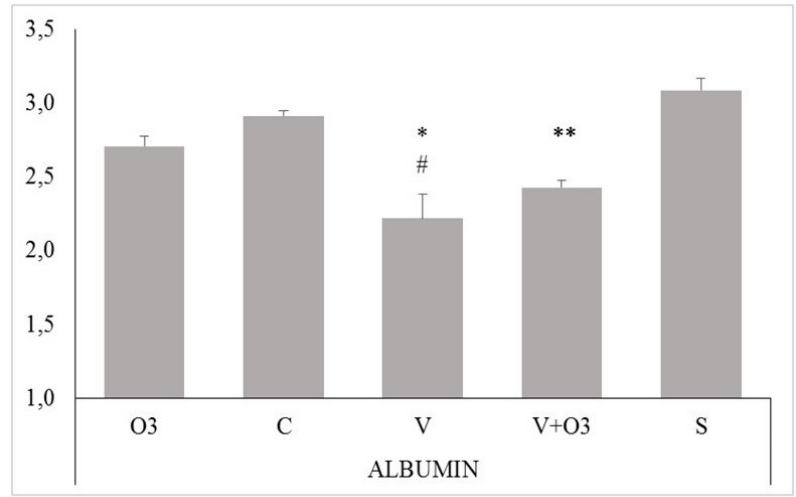

Figure 3 - Serum albumin levels. Statistical significance between the groups is shown by symbols: * V vs $S(p=0.000), \# V+O_{3}$ vs $S(p=0.001)$, $* *$ V vs $C(p=0.000)$

Infection caused a significant increase in IL-1 and TNF-alpha levels as expected 
(Figure 4). This increase was persistant in all infected study groups regardless of the therapy applied. There was no significant difference in IL-10 levels among study groups (Figure 4). Ozone therapy caused an increase in IL-4 levels (Figure 5). Infection caused a decrease in VEGF levels in control and vancomycin groups whereas ozone therapy reversed this decrease (Figure 4).

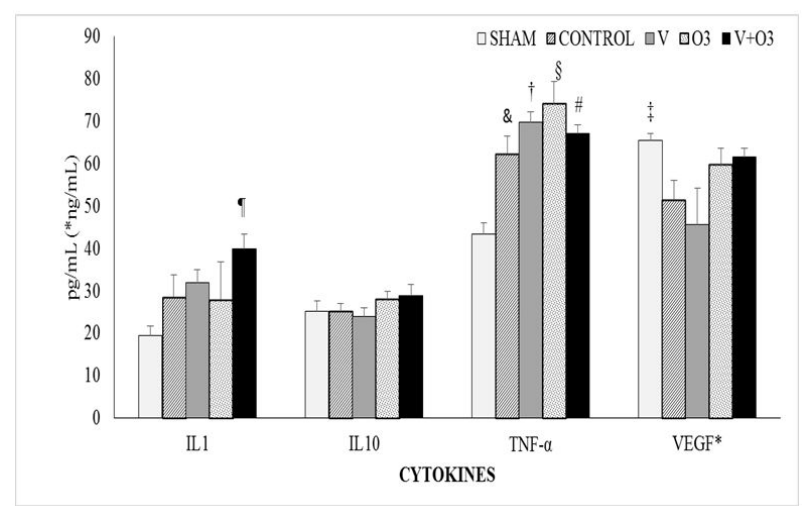

Figure 4 - Serum cytokine levels. Statistical significance between the groups is shown by symbols: $S$ vs $V+O_{3}(p=0.01)$ in IL- $1, \& S$ vs $C$ $(p=0.009), \uparrow S$ vs $\vee(p=0.003), \S \S S$ vs $O_{3}(p=0.003)$, \# $S$ vs $V+O_{3}(p=0.004)$ in TNF-alpha; $\uparrow S$ vs $C(p=0.03)$ in VEGF.

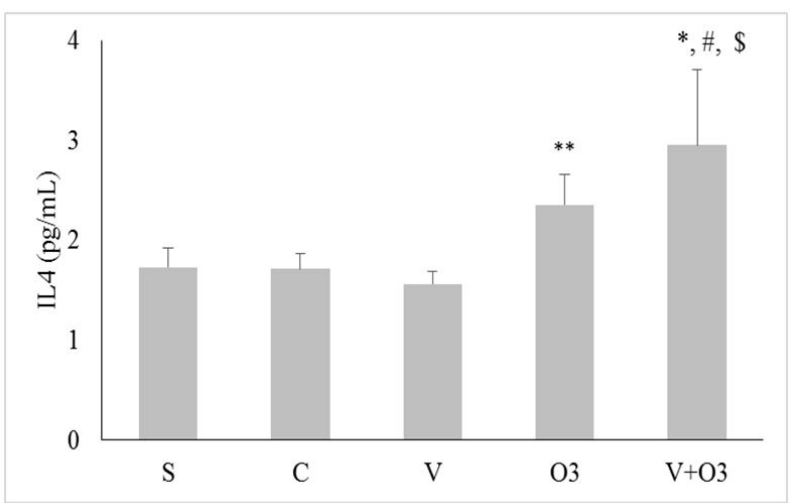

Figure 5 - Serum IL-4 levels. Statistical significance between the groups is shown by symbols: * $\mathrm{S}$ vs $\mathrm{V+}$ $\mathrm{O}_{3}(\mathrm{p}=0.016)$, \# C vs V+ $\mathrm{O}_{3}(\mathrm{p}=0.004), \$ \mathrm{~V}$ vs $\mathrm{V}+\mathrm{O}_{3}$ $(p=0.003), * * \vee v^{\prime} O_{3}(p=0.003)$.

\section{- Discussion}

S. aureus is one of the most common organisms that cause vascular graft infections, especially in early-onset setting. Among staphylococcus strains methicillinresistant staphylococci should be considered as one of the possible causes of infections particularly in vascular surgery patients in the postoperative period ${ }^{1}$.

In vascular graft infections, vancomycin is recommended both in treatment of MRSA infections and initial empiric therapy ${ }^{1}$. Mese et al. $^{10}$ found that vancomycin effectively reduced bacterial growth when administered intraperitoneally in an experimental graft infection model in rats. Yasim et al. ${ }^{12}$ showed the intraperitoneal vancomycin treated group had statistically significant less MRSA growth in a rat model. They also noted that vancomycinsoaked Dacron graft showed no evidence of infection. In our study, we also found that the number of colonies reduced significantly in Group V compared to the Group C ( $p=0.001)$.

Ozone can cause cellular toxicity and serious side effects by inducing oxidative stress. The daily safe dose range of ozone was reported to be $0.5-1 \mathrm{mg} / \mathrm{kg} / \mathrm{d}$ in rats ${ }^{13}$. We preferred to use ozone as $(0.7 \mathrm{mg} / \mathrm{kg} / \mathrm{d})$ since this dose has been previously employed in experimental studies mimicking infectious disorders such as osteomyelitis, peritonitis and mediastinitis ${ }^{14}$.

The antibacterial effect of ozone was investigated in different bacteria. However, its effect after treatment is not clear. A study by Polydorou et al. ${ }^{15}$ showed that the viability of Lactobacillus casei was not influenced by ozone in contrast to Streptococcus mutans (S. mutans), in a tooth cavity model. Ozone therapy reduced the number of $S$. mutans when compared to the untreated controls, however the surviving number of the bacteria was even higher than the reduced numbers. Authors discussed that the recommended doses of ozone application to destroy bacteria were variable and extended application period should be considered for 
more effective therapies against resistant bacteria. Thanomsub et al. ${ }^{16}$ showed ozone not to affect bacterial cell viability enough in bacterial concentrations greater than $10^{6} \mathrm{CFU} /$ $\mathrm{ml}$ even after 150 minutes of treatment.

We didn't observe any antibacterial activity of ozone in our study. In contrast, we observed that ozone increased the number of colonies compared to the Group C. This effect of ozone was statistically not significant $(p=0.172)$. There were more colonies in the $\mathrm{O}_{3}$ group compared with the Group $\mathrm{V}$ and this difference was statistically significant $(p=0.001)$. Silva et $a .^{5}$ reported no statistically significant difference in bactericidal effect between the ozone and $\mathrm{CO}_{2}$ treatments after 24 hours of pneumoperitoneum. The same study reported that the mean of colony numbers in the ozone group increased. In a septic rat model study by Torossian et al. ${ }^{17}$ ozone pre-treatment seemed to reduce the survival rates. Martin-Barrasa et $a .^{18}$ reported that rats which ozone was applied as an adjunct to antibiotic treatment had a worsening of clinical condition compared to animals which treated only with antibiotic in a peritoneal sepsis model.

In our study, the number of colonies in $\mathrm{V}+\mathrm{O}_{3}$ group was lower than the Groups of $\mathrm{O}_{3}$ $(p=0.001)$ and the $C(p=0.001)$. On the other hand, although not statistically significant, the number of colonies in $\mathrm{V}+\mathrm{O}_{3}$ Group was greater than the $V$ Group (Figure 1). This reduction in colony numbers might be due to the vancomycin treatment whereas ozone seems to increase the bacterial growth. Burgassi et al. $^{19}$ showed that in the presence of plasma proteins, both S.aureus and MRSA were protected against ozone and bacterial viability remained complete even with the highest doses of ozone. A systematic review of literature by Azarpazhooh et al. ${ }^{3}$ points out the conflicting evidence of antimicrobial efficacy of ozone while Lynch $^{20}$ comments that ozone can be effective if applied for an adequate time, in sufficient concentrations and into the lesions.

Ozone is powerful oxidant and an unstable molecule at high concentrations. Because it is an unstable molecule, ozone can act as an oxidant or a reductant. Along with its antibacterial effects we investigated the oxidative effects of ozone in our system. Thiol-disulphide homeostasis is an important component of antioxidant protection and immune response. Thiols are affected by oxidation and converted to disulphides. Depending on the oxidant-antioxidant balance of the organism, the reversible disulphide bonds can be reduced to thiol ${ }^{11,21}$. Recently, several studies have emphasized the importance of thiol disulphide homeostasis in infection. Ozyazici et al. ${ }^{22}$ showed that both native and total thiol and the native thiol/total thiol ratio decreased, while disulphide/native thiol, disulphide/total thiol ratios increased in acute appendicitis. Similar results have been observed in different infections ${ }^{6,7}$. Contrary to these studies we found that total thiol and disulphide levels increased and disulphide/ native thiol and disulphide/total thiol ratios decreased in Group $\mathrm{O}_{3}$ (Figure 2). Blood levels of ozone are unpredictable when the agent is used for therapeutic purposes. It is possible that individual metabolic changes contribute to this unclear blood levels.

In our study, we found that the number of colonies increased in ozone applied study groups including $\mathrm{V}+\mathrm{O}_{3}$ (Figure 1 ). We thought that this result may be due to the oxidant property of the ozone molecule on vancomycin disrupting its tricyclic glycosylated peptide structure of vancomycin molecule. Indeed, a study by Dodd et al. also reported $\mathrm{O}_{3}$ to cause stoichiometric elimination of antibacterial activity of many antibacterial molecules including vancomycin ${ }^{23}$. This may be due to that the ozone molecules may attach to vancomycin molecules similarly to the thiols, since vancomycin molecule also has electronemitting potential as thiols.

Proteins such as albumin also have functional -SH groups. Albumin has an important role in serum total antioxidant 
capacity. Albumin levels decrease due to rapid degradation in inflammation and oxidative stress $^{21}$. In this study, albumin levels decreased in all study groups but this decrease was statistically significant only between $\mathrm{V}$ and $\mathrm{V}+\mathrm{O}_{3}$ Groups vs. S Group (Figure 3). This result associated with infection and oxidative stress caused by ozone.

Another important component of infection is the immunological responses to the process. There are also some conflicting reports on ozone's immunological effects. Burleson et al. showed that pulmonary ozone exposure caused a suppression of naturel killer cells activity ${ }^{24}$. Torossian et al. ${ }^{17}$ showed that cytokine levels including TNF-alpha were significantly increased with ozone pretreatment in septic rats. In our study, infection caused a significant increase in IL-1 and TNFalpha levels as expected (Figure 4). This increase was persistent in all infected study groups regardless of the therapy applied. Our findings are in aggrement with studies reporting ozone to induce the production of IL-1 and TNF-alpha in the lung tissue ${ }^{25,26}$. Interestingly, infection caused a decrease in VEGF levels in control and vancomycin groups while ozone therapy reversed this effect in $\mathrm{O}_{3}$ and $\mathrm{V}+\mathrm{O}_{3}$ Groups (Figure 4). Our findings are in agreement with a study by Tandara et al. $\underline{27}$ showing that the $\mathrm{H}_{2} \mathrm{O}_{2}$ formed by ozone treatment to increase production of growth factors, mainly VEGF. VEGF, a procoagulant/proinflammatory agent is a late marker of sepsis ${ }^{28}$. Some studies reported an association between severe sepsis and elevated levels of VEGF in circulation ${ }^{28,29}$. On the other hand, VEGF levels decreased in severe pulmonary disease, because of the failed repair mechanism ${ }^{29,30}$. Another antiinflammatory cytokine, IL4 also increased in $\mathrm{O}_{3}$ and $\mathrm{V}+\mathrm{O}_{3}$ Groups (Figure 5). Although one may argue that increased levels of IL-4 can be an indicator of protective effects of ozone in inflammatory processes, decreased VEGF levels contradict this suggestion. Overall, our findings of VEGF and IL4, along with TNF and
IL-1 data, suggest no clear therapeutical role of ozone in infection therapy.

\section{- Conclusions}

Althoughozoneisapowerfuldisinfectant we observed no additional antibacterial effect of ozone in experimental vascular graft infection when used in combination with standard antimicrobial therapy. At the same time, we observed diverse effects of ozone on thiol-disulphide homeostasis and inflammatory cytokines. Ozone is an unstable molecule, and its therapeutic effects and states in metabolic reactions are unpredictable. Thus, ozone should be approached with caution as a supportive therapy in infectious diseases and inflammation.

\section{- References}

1. Young MH, Upchurch GR, Jr., Malani PN. Vascular graft infections. Infect Dis Clin North Am. 2012;26:41-56. PMID: 22284375.

2. Dickinson GM, Bisno AL. Antimicrobial prophylaxis of infection. Infect Dis Clin North Am. 1995;9:783-804. PMID: 7490444.

3. Azarpazhooh A, Limeback $H$. The application of ozone in dentistry: a systematic review of literature. J Dent. 2008;36:104-16. PMID: 18166260.

4. Martinez-Sanchez G, Al-Dalain SM, Menendez S, Re L, Giuliani A, CandelarioJalil E, Alvarez H, Fernandez-Montequin JI, Leon OS. Therapeutic efficacy of ozone in patients with diabetic foot. Eur J Pharmacol. 2005;523:151-61. PMID: 16198334.

5. Silva RA, Garotti JE, Silva RS, Navarini A, Pacheco AM, Jr. Analysis of the bactericidal effect of ozone pneumoperitoneum. Acta Cir Bras. 2009;24:124-7. PMID: 19377781.

6. Kara SS, Erel O, Demirdag TB, Cura Yayla BC, Gulhan B, Neselioglu S, Polat $M$, Kalkan G, Tapisiz A, Tezer H. Alteration of thiol-disulphide homeostasis in acute tonsillopharyngitis. Redox Rep. 2016:1-5. PMID: 27096391.

7. Kolgelier S, Ergin M, Demir LS, Inkaya AC, Demir NA, Alisik M, Erel O. Impaired thioldisulphide balance in acute brucellosis. Jpn J 
Infect Dis. 2016. [Epub ahead of print]. PMID: 27795469.

8. Cirioni O, Mocchegiani F, Ghiselli R, Silvestri C, Gabrielli E, Marchionni E, Orlando F, Nicolini D, Risaliti A, Giacometti A. Daptomycin and rifampin alone and in combination prevent vascular graft biofilm formation and emergence of antibiotic resistance in a subcutaneous rat pouch model of staphylococcal infection. Eur J Vasc Endovasc Surg. 2010;40:817-22. PMID: 20869272.

9. Cakmak A, Cirpanli Y, Bilensoy E, Yorganci K, Calis S, Saribas Z, Kaynaroglu V. Antibacterial activity of triclosan chitosan coated graft on hernia graft infection model. Int J Pharm. 2009;381:214-9. PMID: 19501640.

10. Mese B, Bozoglan O, Elveren S, Eroglu E, Gul M, Celik A, Ciralik H, Yildirimdemir HI, Yasim A. Efficacy of linezolid, teicoplanin, and vancomycin in prevention of an experimental polytetrafluoroethylene graft infection model caused by methicillin-resistant staphylococcus aureus. Med Sci Monit. 2015;21:909-14. PMID: 25819685.

11. Erel O, Neselioglu S. A novel and automated assay for thiol/disulphide homeostasis. Clin Biochem. 2014;47:326-32. PMID: 25304913.

12. Yasim A, Gul M, Atahan E, Ciragil P, Aral M, Ergun Y. Efficacy of vancomycin, teicoplanin and fusidic acid as prophylactic agents in prevention of vascular graft infection: An experimental study in rat. Eur J Vasc Endovasc Surg. 2006;31:274-9. PMID: 16360328.

13. Sun W, Pei L. Ozone preconditioning and exposure to ketamine attenuates hepatic inflammation in septic rats. Arch Med Sci. 2012;8:918-23. PMID: 23185204.

14. Gulmen S, Kurtoglu T, Meteoglu I, Kaya S, Okutan $\mathrm{H}$. Ozone therapy as an adjunct to vancomycin enhances bacterial elimination in methicillin resistant staphylococcus aureus mediastinitis. J Surg Res. 2013;185:64-9. PMID: 23809152.

15. Polydorou O, Halili A, Wittmer A, Pelz K, Hahn P. The antibacterial effect of gas ozone after 2 months of in vitro evaluation. Clin Oral Investig. 2012;16:545-50. PMID: 21331635.

16. Thanomsub B, Anupunpisit V, Chanphetch $\mathrm{S}$, Watcharachaipong T, Poonkhum R, Srisukonth C. Effects of ozone treatment on cell growth and ultrastructural changes in bacteria. J Gen Appl Microbiol. 2002;48:1939. PMID: 12469318.
17. Torossian A, Ruehlmann S, Eberhart L, Middeke $M$, Wulf $H$, Bauhofer A. Pretreatment with ozonized oxygen (03) aggravates inflammation in septic rats. Inflamm Res. 2004;53 Suppl 2:S122-5. PMID: 15338062.

18. Martin-Barrasa JL, Mendez Cordovez C, Espinosa de los Monteros y Zayas A, Juste de Santa Ana MC, Clavo Varas B, Herraez Thomas P, Bordes Benitez A, MontoyaAlonso JA, Garcia-Bello M, Artiles Campelo F, Tejedor-Junco MT. Rectal pre-treatment with ozonized oxygen (o3) aggravates clinic status in septic rats treated with amoxicillin/ clavulanate. Enferm Infecc Microbiol Clin. 2015;33:469-75. PMID: 25459192.

19. Burgassi S, Zanardi I, Travagli V, Montomoli E, Bocci V. How much ozone bactericidal activity is compromised by plasma components? J Appl Microbiol. 2009;106:1715-21. PMID: 19226394.

20. Lynch E. Comment on "the application of ozone in dentistry: a systematic review of the literature". J Dent. 2009;37:406-10. PMID: 19303187.

21. Turell L, Radi R, Alvarez B. The thiol pool in human plasma: the central contribution of albumin to redox processes. Free Radic Biol Med. 2013;65:244-53. PMID: 23747983.

22. Ozyazici S, Karateke F, Turan U, Kuvvetli A, Kilavuz H, Karakaya B, Ozaltun P, Alisik M, Erel $O$. A novel oxidative stress mediator in acute appendicitis: Thiol/disulphide homeostasis. Mediators Inflamm. 2016;2016:6761050. PMID: 27642237.

23. Dodd MC, Kohler HP, von Gunten U. Oxidation of antibacterial compounds by ozone and hydroxyl radical: elimination of biological activity during aqueous ozonation processes. Environ Sci Technol. 2009;43:2498-504. PMID: 19452907.

24. Burleson GR, Keyes LL, Stutzman JD. Immunosuppression of pulmonary natural killer activity by exposure to ozone. Immunopharmacol Immunotoxicol. 1989;11:715-35. PMID: 2628483.

25. Fakhrzadeh L, Laskin JD, Laskin DL. Ozoneinduced production of nitric oxide and tnfalpha and tissue injury are dependent on nf-kappab p50. Am J Physiol Lung Cell Mol Physiol. 2004;287:L279-85. PMID: 15064226.

26. Park JW, Taube C, Swasey C, Kodama T, Joetham A, Balhorn A, Takeda K, Miyahara N, 
Allen CB, Dakhama A, Kim SH, Dinarello CA, Gelfand EW. Interleukin-1 receptor antagonist attenuates airway hyperresponsiveness following exposure to ozone. Am J Respir Cell Mol Biol. 2004;30:830-6. PMID: 14754758.

27. Tandara AA, Mustoe TA. Oxygen in wound healing--more than a nutrient. World J Surg. 2004;28:294-300. PMID: 14961188.

28. Yano K, Liaw PC, Mullington JM, Shih SC, Okada H, Bodyak N, Kang PM, Toltl L, Belikoff B, Buras J, Simms BT, Mizgerd JP, Carmeliet P, Karumanchi SA, Aird WC. Vascular endothelial growth factor is an important determinant of sepsis morbidity and mortality. J Exp Med. 2006;203:1447-58. PMID: 18852292.

29. Karlsson S, Pettila V, Tenhunen J, Lund V,
HovilehtoS, Ruokonen E. Vascular endothelial growth factor in severe sepsis and septic shock. Anesth Analg. 2008;106:1820-6. PMID: 18499616.

30. Papp A, Bene Z, Gaspar I, Nagy B, Jr., Kadar L, Marialigeti T, Banfi A, Baktai G, Balla G, Nagy B. Decreased vegf level is associated with elevated ferritin concentration in bronchoalveolar lavage fluid of children with interstitial lung diseases. Respiration. 2015;90:443-50. PMID: 26473738.

\section{Acknowledgement}

To Ms. Ilay Turkmen for conducting ELISA analyses.

\section{Correspondence:}

Barcin Ozturk

University of Adnan Menderes, School

of Medicine

Department of Infectious Diseases and

Clinical Microbiology

09010 Kepez Location Aydin - Turkey

Phone: 0902564441256

barcinozturk@gmail.com

Received: Nov 05, 2016

Review: Jan 06, 2017

Accepted: Feb 03, 2017
Conflict of interest: none

Financial source: Adnan Menderes University (fund no TFP-13020)

\footnotetext{
${ }^{1}$ Research performed at University of Adnan Menderes, School of Medicine, Experimental Animal Production and Research Laboratory, Aydin, Turkey and University of Yildirim Beyazit, School of Medicine Department of Medical Biochemistry, Ankara, Turkey.
} 